Case Report

\title{
Total Hip Arthroplasty in a Patient with Oto-Spondylo-Megaepiphyseal Dysplasia Planned by Three-Dimensional Motion Analyses and Full-Scale Three-Dimensional Plaster Model of Bones
}

\author{
Takeyuki Tanaka $\mathbb{D}^{1},{ }^{1}$ Hideya Ito, ${ }^{2}$ Hirofumi Oshima, ${ }^{1}$ Nobuhiko Haga, ${ }^{3}$ \\ and Sakae Tanaka ${ }^{1}$ \\ ${ }^{1}$ Department of Orthopaedic Surgery, Faculty of Medicine, The University of Tokyo, 7-3-1 Hongo, Bunkyo-ku, Tokyo \\ 113-8655, Japan \\ ${ }^{2}$ Bone and Joint Orthopaedic Surgery, Japanese Red Cross Medical Center, 4-1-22 Hiroo, Shibuya-ku, Tokyo 150-8935, Japan \\ ${ }^{3}$ Department of Rehabilitation Medicine, Graduate School of Medicine, The University of Tokyo, 7-3-1 Hongo, Bunkyo-ku, Tokyo \\ 113-8655, Japan
}

Correspondence should be addressed to Takeyuki Tanaka; tanakata-ort@h.u-tokyo.ac.jp

Received 5 September 2017; Accepted 3 January 2018; Published 23 January 2018

Academic Editor: Paul E. Di Cesare

Copyright ( $) 2018$ Takeyuki Tanaka et al. This is an open access article distributed under the Creative Commons Attribution License, which permits unrestricted use, distribution, and reproduction in any medium, provided the original work is properly cited.

\begin{abstract}
We present the case of a 28-year-old woman with oto-spondylo-megaepiphyseal dysplasia, which is a rare skeletal disorder, who underwent bilateral total hip arthroplasty. Full-scale three-dimensional plaster model of the acetabulum and the femur provided us with a feasible preoperative plan. Pre- and postoperative three-dimensional motion analyses proved a significant improvement in her ambulation and confirmed the efficacy of total hip arthroplasty. In conclusion, full-scale three-dimensional plaster models of the bone and three-dimensional motion analyses were useful for total hip arthroplasty in patients with skeletal dysplasia.
\end{abstract}

\section{Introduction}

Oto-spondylo-megaepiphyseal dysplasia (OSMED) is a rare skeletal disorder characterized by a flat midface, severe sensorineural hearing loss, and early-onset osteoarthritis. Cleft palate and micrognathia are also common findings [1]. Researchers have identified gene abnormalities related to type II and type XI collagen [2, 3]. Although about 30 patients have been reported in the literature $[2,4-6]$, there is a paucity of published data regarding the treatment of locomotive dysfunctions.

Total hip arthroplasty (THA) is an established modality of treatment for patients with osteoarthritis of the hip joint, and preoperative planning is mandatory for preparing optimal implants [7]. Although the radiographic templating techniques achieve satisfactory results in most cases $[8,9]$, they are not always applicable to patients with unusual skeletal deformities. Moreover, multiple involvements of the joints make it difficult to assess the contribution of the hip joints to gait disturbance. However, recent advancements in computer technology could help orthopedic surgeons not only to plan but also to evaluate the efficacy of hip surgery in these patients $[10,11]$. The case of a 28 -year-old woman with OSMED who suffered from multiple joint deformities, including bilateral hip joints, is presented.

\section{Case Presentation}

A 28-year-old woman was referred for a gait disturbance with reduced range of motion (ROM) of bilateral hip joints and bilateral hip pain. At the age of 2 years, she had been diagnosed as having bilateral hearing loss and had undergone 


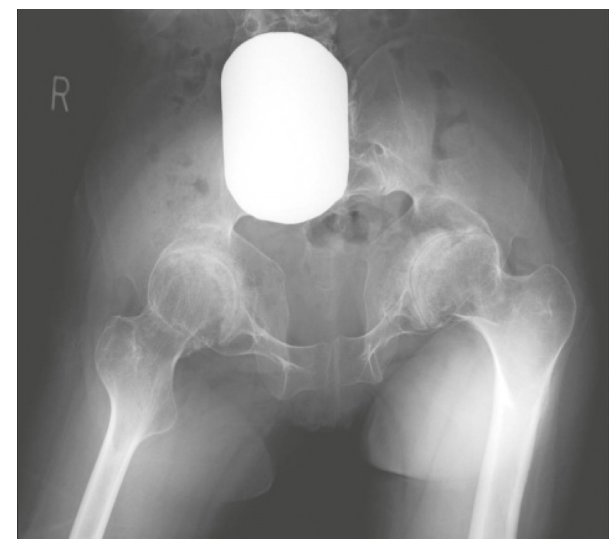

FIGURE 1: Preoperative radiograph showing end-stage osteoarthritis of the hip joints associated with large femoral heads.

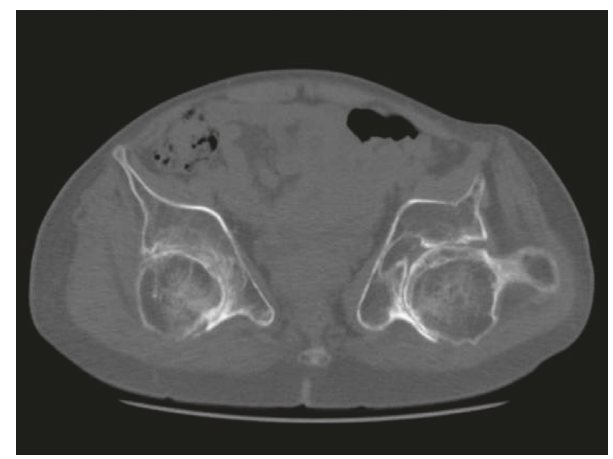

Figure 2: Axial CT image of the hip joints, demonstrating significant retroversion of the acetabulum.

surgery to correct a cleft palate. From the age of 20 years, she had noticed stiffness of the hip joints and difficulty in walking. At the age of 23 years, clinical geneticists had diagnosed her as having OSMED and identified a COL2A1 mutation relating to type II collagen.

At the time of the referral, although she could walk for a few minutes using 2 Lofstrand crutches, she used a wheelchair in her daily life. Her height was $155 \mathrm{~cm}(-0.1$ $\mathrm{SD})$, and her weight was $47 \mathrm{~kg}$ (-0.8 SD). Physical examination revealed significantly reduced ROM in the limb joints and spine; ROM of both hip joints showed $60^{\circ}$ of flexion contracture, $80^{\circ}$ of flexion, $0^{\circ}$ of abduction, and $10^{\circ}$ of adduction. The Harris Hip Score (HHS) [12] was 19 on the right and 20 on the left. Radiographs showed multiple changes of the skeleton, including end-stage osteoarthritis of the hip joints (Figure 1) and knee joints and hyperlordosis of the lumbar spine. The computed tomography (CT) images of the hip joints revealed significant retroversion of the acetabulum (Figure 2). A three-dimensional motion analysis system (VICON MX, SGI, Tokyo, Japan) was used to analyze her standing up and her gait; fixed anterior tilting of the pelvis and limited mobility of the lumbar spine were demonstrated. Furthermore, it also revealed that her center of gravity deviated anteriorly because she could not compensate for severe flexion contractures of bilateral hip joints due to limited mobility of the lumbar spine. Therefore, it was possible to identify that hip dysfunction had a major impact on gait disturbance (Figure 3).

Thus, bilateral THA was considered the treatment of choice. For planning, full-scale three-dimensional plaster models of the pelvis and femora were produced with an inkjet printer method using CT data (Next21 K.K., Tokyo, Japan). The acetabular cavity was aspherical, and the wall was thin even in the safe zone [13] (Figure 4). To fill the vault, the diameter of the acetabular component needs to be more than 66 millimeters. When a 68-millimeter diameter hemisphere was set at $0^{\circ}$ of anteversion, its posterior part projected backward from the acetabulum, and its anterior part was deep in the bony wall (Figure 5). The goal was to gain good ROM without impingement. Thus, the plan was to fix a 68- or 70-millimeter diameter acetabular shell at $40^{\circ}$ of abduction and $0^{\circ}$ of anteversion in terms of the anatomical measurements [14], remove a significant amount of the bone from the anterior and anteroinferior parts of the acetabulum, use a 44-millimeter head, and fix the stem at $30^{\circ}$ of anteversion (Figure 6). It was also considered vital to avoid reaming too deeply to avoid penetration of the acetabular wall.

The patient underwent right uncemented THA through a posterolateral approach. The acetabular component was a $68 \mathrm{~mm}$, hemispherical shell (Trident, Stryker Orthopaedics, Mahwah, NJ, USA) with a highly cross-linked polyethylene liner (X3, Stryker Orthopaedics) and two transfixing screws. The femoral component was a tapered wedge stem with a neck shaft angle of $127^{\circ}$ (Accolade TMZF, Stryker Orthopaedics) with a $44 \mathrm{~mm}(+4)$ modular head. These components were fixed at the same angle as at preoperative planning. Passive motion was possible from $30^{\circ}$ to $90^{\circ}$ in the sagittal plane.

Two months later, she underwent left THA through a posterolateral approach. The acetabular component was a $68 \mathrm{~mm}$ Trident shell with an X3 liner and 2 transfixing screws. The femoral component was an Accolade TMZF stem with a neck shaft angle of $132^{\circ}$ with a $44 \mathrm{~mm}(+0)$ modular head. This time, the shell was placed at $35^{\circ}$ of abduction and $10^{\circ}$ of anteversion. Passive motion was possible from $30^{\circ}$ to $100^{\circ}$ in the sagittal plane. Although the surgery was uncomplicated, migration of the shell was found 2 weeks later. Thus, the unstable shell was removed, and a $70 \mathrm{~mm}$ Trident shell was placed with 6 transfixing screws at $45^{\circ}$ of abduction and $10^{\circ}$ of anteversion.

At 1.5-year follow-up, the patient had no hip pain and could walk without walking aids for about 10 minutes. Even though the flexion contracture had remained in both hip joints after surgery, ROM improved with active exercise. Thus, passive ROM of the right hip showed $100^{\circ}$ of flexion with no flexion contracture and $20^{\circ}$ of abduction and that of the left hip showed $80^{\circ}$ of flexion with no flexion contracture and $10^{\circ}$ of abduction. The HHS was 74 on the right and 73 on the left. Radiographs demonstrated stable components (Figure 7). Three-dimensional motion analysis demonstrated that her center of gravity had shifted posteriorly because of the improvement of the flexion contractures of bilateral hip joints and that her gait pattern improved significantly (Figure 8). 

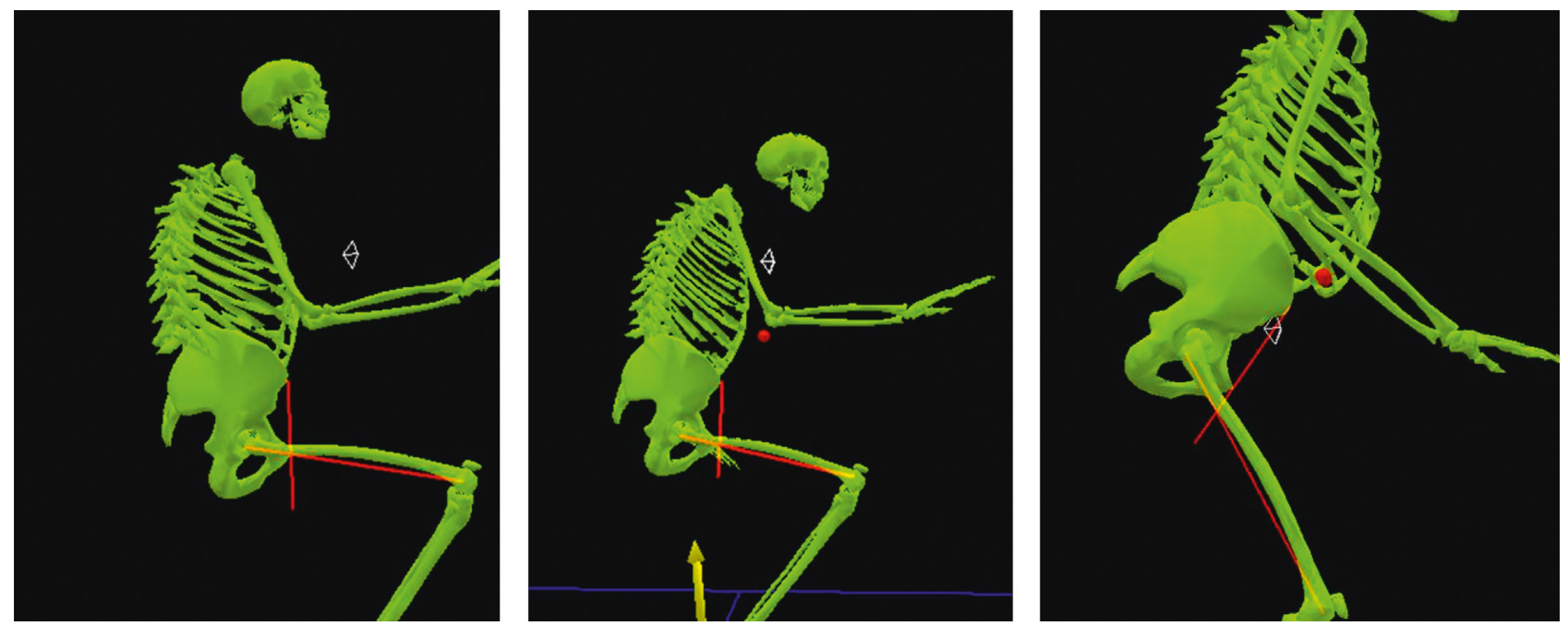

Figure 3: Preoperative three-dimensional motion analysis demonstrates fixed anterior tilting of the pelvis, limited mobility of the lumbar spine, and anterior deviation of the center of gravity.

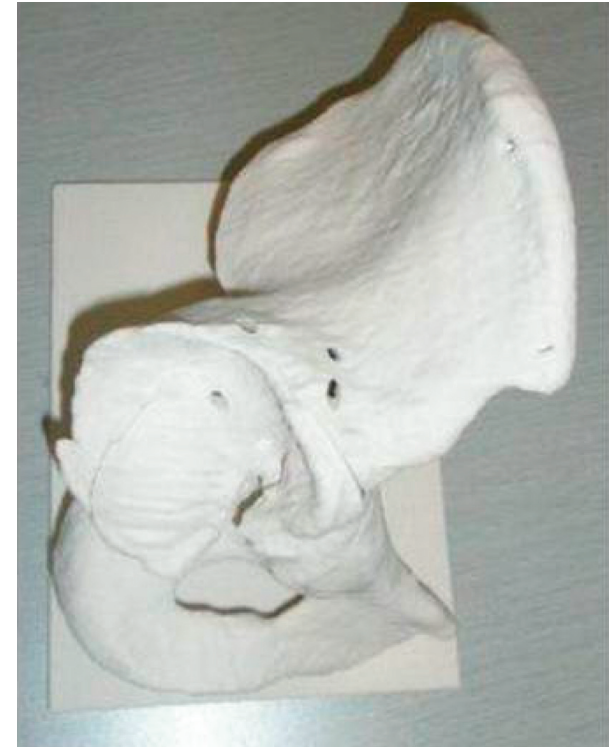

FIGURE 4: Full-scale three-dimensional plaster models of the pelvis, showing the aspherical acetabular cavity and the thin acetabular wall.

\section{Discussion}

Recent advancements in computer technology have made it possible for orthopedic surgeons to use various methods for planning THA, including three-dimensional templating [15], solid bone models [16], and simulation surgery in virtual space $[17,18]$. Moreover, three-dimensional motion analysis provides surgeons with objective assessment of the efficacy of THA $[10,11,19]$. Although these could be useful for patients with inherited skeletal disorders, only two cases have been previously reported [20]. Therefore, we use threedimensional motion analysis to the patients with the complicated deformity in THA. The three-dimensional motion analysis may be difficult to predict the postoperative postural change; however, the information gained by the

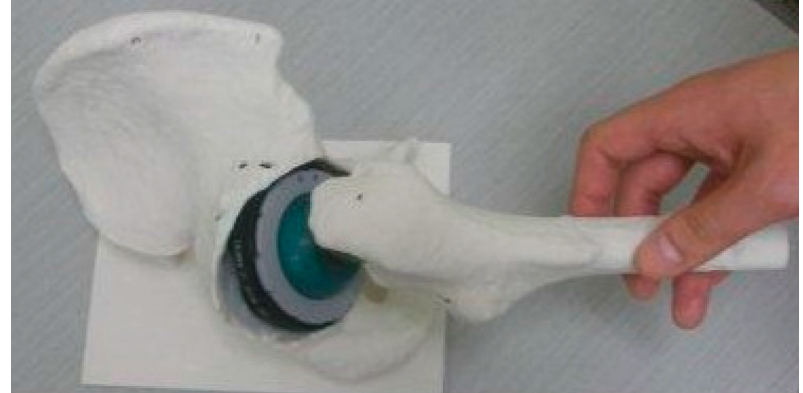

FIGURE 5: Setting a 68-millimeter diameter hemisphere at $0^{\circ}$ of anteversion on the plaster model. This demonstrates that its posterior part projects backward from the acetabulum and its anterior part is deep in the bony wall. To avoid bony impingement, a significant amount of the bone needs to be removed.

present case will give us the specific information about the posture in such patients suffering from skeletal disorders.

In the present case, arthritic changes of the knee joints and hyperlordosis of the lumbar spine were evident. To determine the indication for THA, a preoperative threedimensional motion analysis was performed; it demonstrated that hip dysfunction had a major impact on gait disturbance. Therefore, positive results were anticipated with THA. Full-scale three-dimensional models provided useful information on the size and position of the prostheses, the depth of acetabular reaming, and the extent of the bone that should be removed to avoid bony impingement and gain good ROM. After the second THA, however, migration of the acetabular shell occurred in two weeks. The cause of this complication was probably insufficient anchorage of the shell. The follow-up three-dimensional motion analysis confirmed the positive results of THA.

Compared with simulation surgery in virtual space, three-dimensional models seem to be less sophisticated. However, the possible advantage of these models is that surgeons are able to place the actual implants on the models 


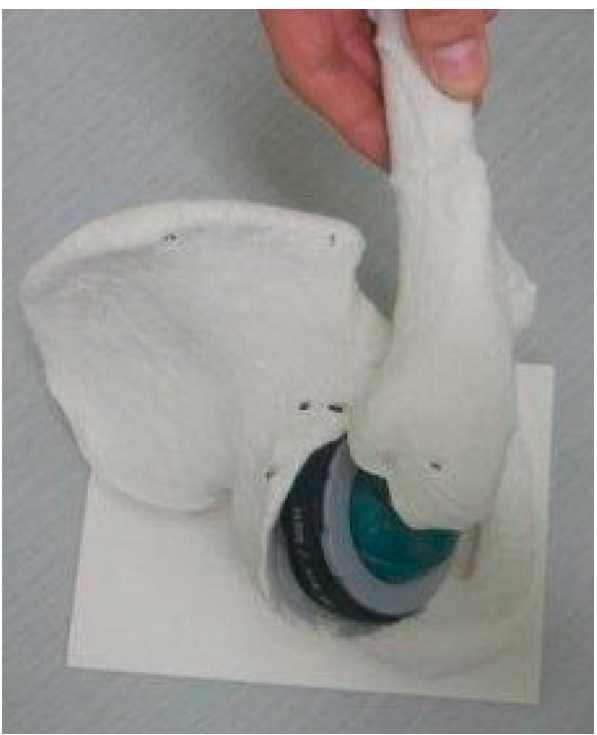

FIGURE 6: Simulation of surgery, using a 68-millimeter diameter acetabular shell, a tapered wedge stem, and a 44-millimeter femoral head. Bony impingement occurs between the anterior and anteroinferior acetabulum and the proximal femur.

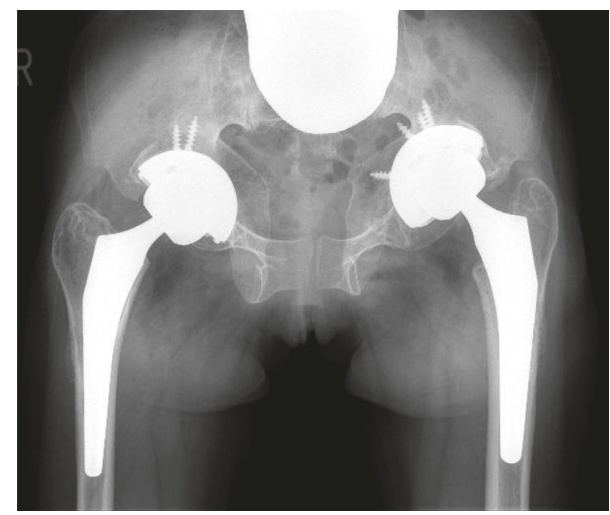

Figure 7: Postoperative radiograph of the hip joints, taken 1.5 years after the last surgery, demonstrating well-fixed components.

as a surgical simulation and grip a structural image of the skeleton [16, 21]. In particular, this model is useful for patients with skeletal dysplasia because unusual and severe skeletal deformities are common findings in these individuals.

In conclusion, based on the experience of the present case, three-dimensional motion analysis appears to be useful not only for postoperative evaluation but also for preoperative assessment, especially in patients with multiple joint disorders. In these patients, it is often difficult to identify the joint that should be treated first to alleviate gait disturbance. A three-dimensional motion analysis provides surgeons with scientific support for surgical intervention of the particular joint.

\section{Ethical Approval}

This study was approved by the Ethics Committee of the University of Tokyo Hospital.

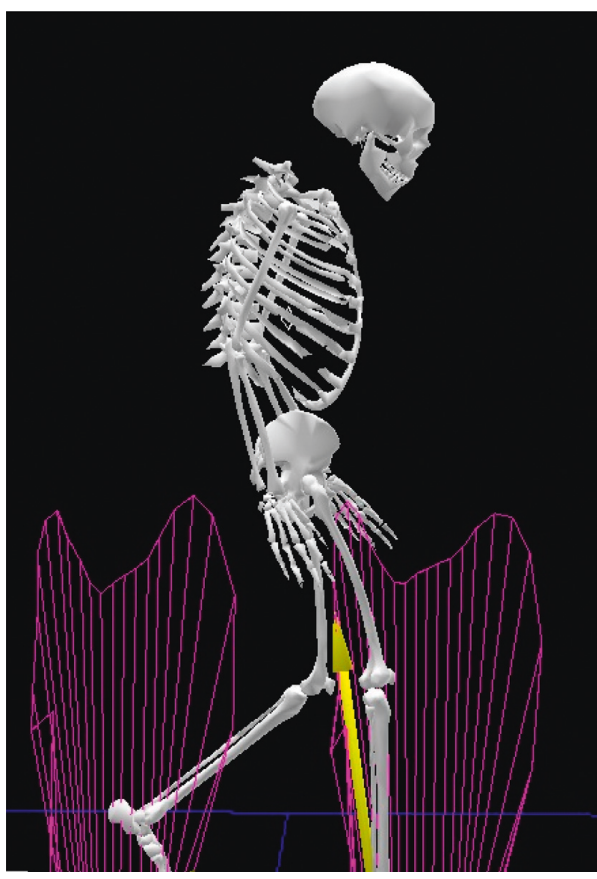

Figure 8: Postoperative three-dimensional motion analysis demonstrates that the patient's gait pattern has improved significantly.

\section{Consent}

Informed consent was obtained from the patient for publication of this case report.

\section{Conflicts of Interest}

The authors declare that they have no conflicts of interest regarding the publication of this article.

\section{Acknowledgments}

The authors thank Dr. Yoshio Takatori for his valuable suggestions in preparing this manuscript.

\section{References}

[1] A. Giedion, M. Brandner, J. Lecannellier et al., "Otospondylo-megaepiphyseal dysplasia (OSMED)," Helvetica Paediatrica Acta, vol. 37, no. 4, pp. 361-380, 1982.

[2] Y. Miyamoto, E. Nakashima, H. Hiraoka, H. Ohashi, and S. Ikegawa, "A type II collagen mutation also results in otospondylo-megaepiphyseal dysplasia," Human Genetics, vol. 118, no. 2, pp. 175-178, 2005.

[3] M. A. van Steensel, P. Buma, M. C. de Waal Malefijt, F. H. van den Hoogen, and H. G. Brunner, "Oto-spondylomegaepiphyseal dysplasia (OSMED): clinical description of three patients homozygous for a missense mutation in the COL11A2 gene," American Journal of Medical Genetics, vol. 70, no. 3, pp. 315-323, 1997.

[4] S. A. Temtamy, M. Mannikko, G. M. Abdel-Salam, N. A. Hassan, L. Ala-Kokko, and H. H. Afifi, "Oto-spondylomegaepiphyseal dysplasia (OSMED): clinical and radiological findings in sibs homozygous for premature stop codon 
mutation in the COL11A2 gene," American Journal of Medical Genetics Part A, vol. 140, no. 11, pp. 1189-1195, 2006.

[5] T. Avcin, O. Makitie, M. Susic et al., "Early-onset osteoarthritis due to otospondylomegaepiphyseal dysplasia in a family with a novel splicing mutation of the COL11A2 gene," Journal of Rheumatology, vol. 35, no. 5, pp. 920-926, 2008.

[6] K. Karaer, R. O. Rosti, D. Torun, H. T. Sanal, M. Bahce, and S. Guran, "A case with oto-spondylo-mega-epiphysealdysplasia (OSMED): the clinical recognition and differential diagnosis," Turkish Journal of Pediatrics, vol. 53, no. 3, pp. 346-351, 2011.

[7] L. W. Carter, D. O. Stovall, and T. R. Young, "Determination of accuracy of preoperative templating of noncemented femoral prosthesis," Journal of Arthroplasty, vol. 10, no. 4, pp. 507-513, 1995.

[8] S. Eggli, M. Pisan, and M. E. Muller, "The value of preoperative planning for total hip arthroplasty," Journal of Bone and Joint Surgery, vol. 80, no. 3, pp. 382-390, 1998.

[9] A. Gonzarez Della Valle, G. Slullitel, F. Piccaluga, and E. A. Salvati, "The precision and usefulness of preoperative planning for cemented and hybrid primary total hip arthroplasty," Journal of Arthroplasty, vol. 20, no. 1, pp. 51-58, 2005.

[10] M. Perron, F. Malouin, H. Moffet, and B. J. McFadyen, "Three-dimensional gait analysis in women with a total hip arthroplasty," Clinical Biomechanics, vol. 15, no. 7, pp. 504515, 2000.

[11] M. Pospischill, A. Kranzl, B. Attwenger, and K. Knahr, "Minimally invasive compared with traditional transgluteal approach for total hip arthroplasty: a comparative gait analysis," Journal of Bone and Joint Surgery-American, vol. 92, no. 2, pp. 328-337, 2010.

[12] W. H. Harris, "Traumatic arthritis of the hip after dislocation and acetabular fractures: treatment by mold arthroplasty," Journal of Bone \& Joint Surgery, vol. 51, no. 4, pp. 737-755, 1969.

[13] R. C. Wasielewski, L. A. Cooperstein, M. P. Kruger, and H. E. Rubash, "Acetabular anatomy and the transacetabular fixation of screws in total hip arthroplasty," Journal of Bone \& Joint Surgery, vol. 72, no. 4, pp. 501-508, 1990.

[14] D. H. Murray, "The definition and measurement of acetabular orientation," Journal of Bone and Joint Surgery, vol. 75, no. 2, pp. 228-232, 1993.

[15] M. Viceconti, R. Lattanzi, B. Antonietti et al., "CT-based surgical planning software improves the accuracy of total hip replacement preoperative planning," Medical Engineering \& Physics, vol. 25, no. 5, pp. 371-377, 2003.

[16] J. F. John, R. E. Talbert, J. K. Taylor, and W. L. Bargar, "Use of acetabular models in planning complex acetabular reconstructions," Journal of Arthroplasty, vol. 10, no. 5, pp. 661-666, 1995.

[17] P. C. Nobel, N. Sugano, J. D. Johnson et al., "Computer simulation: how can it help the surgeon optimize implant position?" Clinical Orthopaedics and Related Research, vol. 417, pp. 242-252, 2003.

[18] L. Petrolo, D. Testi, F. Taddei, and M. Viceconti, "Effect of a virtual reality interface on the learning curve and on the accuracy of a surgical planner for total hip replacement," Computer Methods and Programs in Biomedicine, vol. 97, no. 1, pp. 86-91, 2010.

[19] A. M. Ewen, S. Stewart, A. St Clair Gibson, S. N. Kashyap, and N. Caplan, "Post-operative gait analysis in total hip replacement patients-a review of current literature and metaanalysis," Gait and Posture, vol. 36, no. 1, pp. 1-6, 2012.
[20] E. Tassinari, L. Boriani, F. Traina, D. Dallari, A. Toni, and A. Giunti, "Bilateral total hip arthroplasty in MorquioBrailsford's syndrome: a report of two cases," La Chirurgia degli Organi di Movimento, vol. 92, no. 2, pp. 123-126, 2008.

[21] M. Yamazaki, A. Okawa, T. Akazawa, and M. Koda, "Usefulness of 3-dimensional full-scale modeling for preoperative simulation of surgery in a patient with old unilateral cervical fracture-dislocation," Spine, vol. 32, no. 18, pp. E532-536, 2007. 


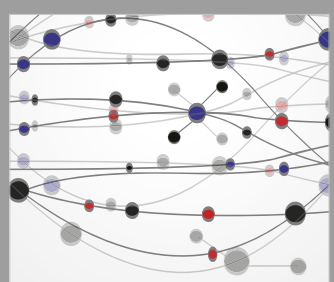

The Scientific World Journal
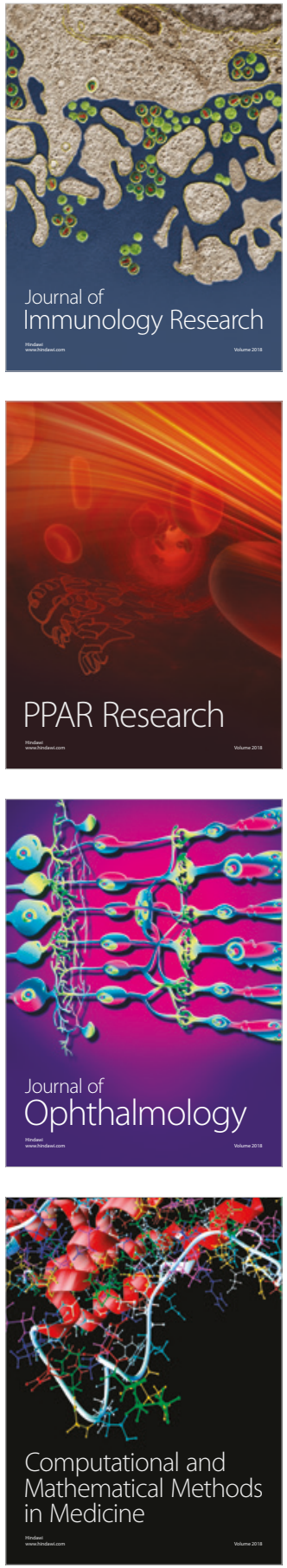

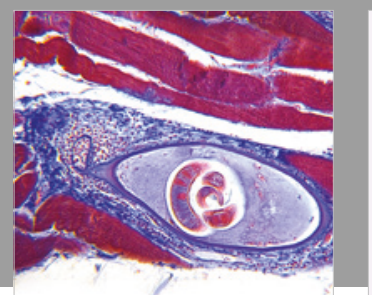

Gastroenterology Research and Practice

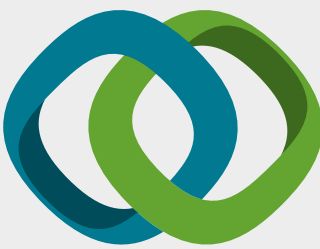

\section{Hindawi}

Submit your manuscripts at

www.hindawi.com
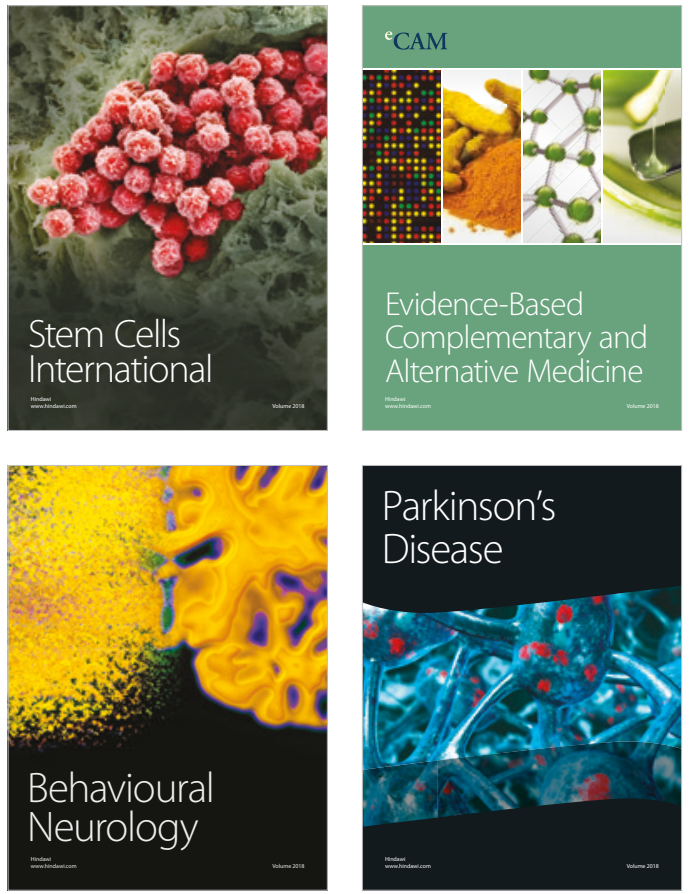

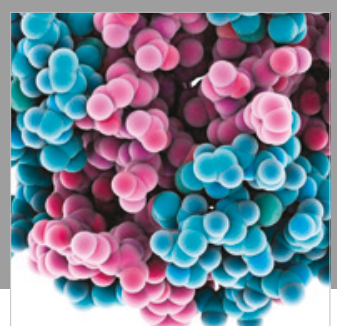

ournal of

Diabetes Research

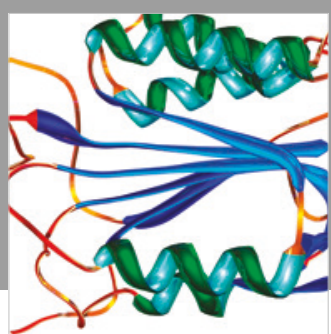

Disease Markers
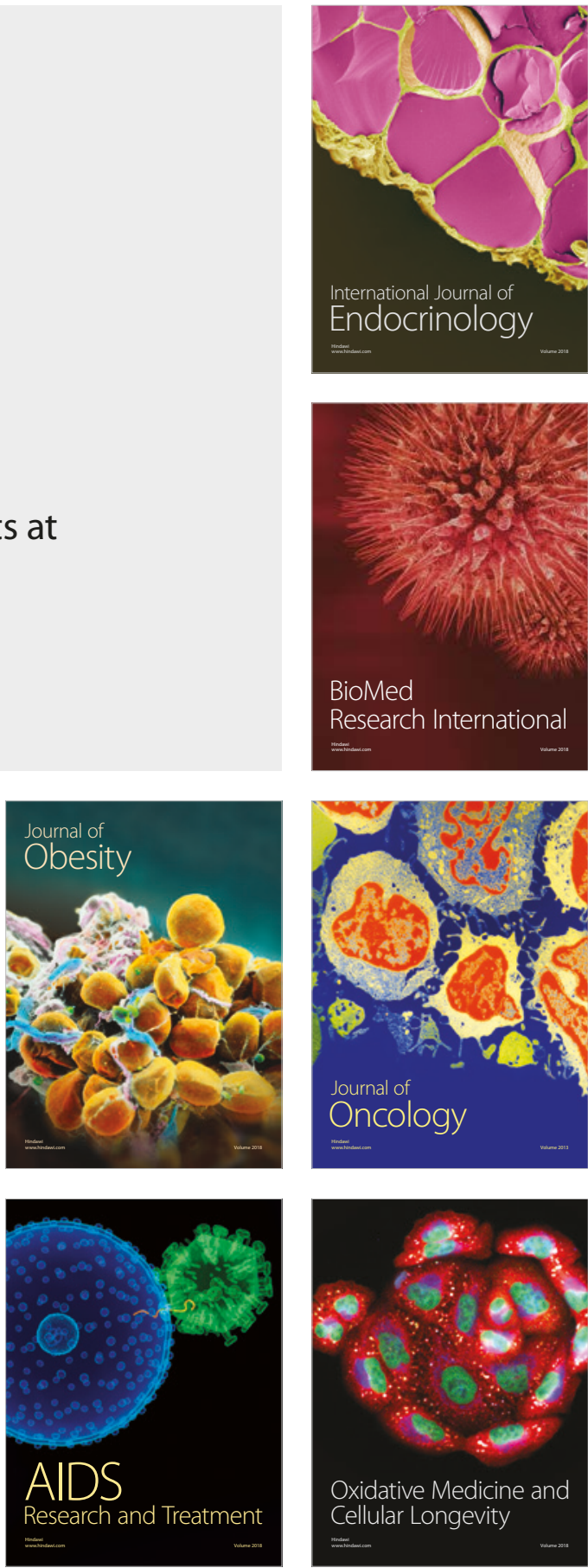